Smoking

\section{Defining residential tobacco home policies: a behavioural and cultural perspective}

\section{Hovell, J Daniel}

\section{Commentary on the paper by Spencer et al (see page 670)}

$\mathrm{P}$ assive smoke exposure (PSE) is carcinogenic, linked to cardiovascular and respiratory diseases, increased risk for sudden infant death, and increased severity of asthma, and is generally harmful. ${ }^{1}$

According to the behavioural ecological model (BEM), smoking and passive smoke exposure are behaviours influenced by interacting physiological, environmental, and cultural contingencies. ${ }^{3}$ Social models, criticism, and praise serve as powerful reinforcing contingencies of lifestyle practices. These interact prominently with physiological and community based contingencies. For instance, once an individual is prompted by the industry to start smoking, nicotine addiction adds physiological consequences for smoking (for example, increased alertness) and for not smoking (for example, increased anxiety). These interact with social contingencies promoted by the industry, media, and social reinforcement from members of personal networks to strengthen the addiction. The strength of the addiction is dependent on the biological addiction to nicotine and the density of reinforcement from social networks. Fortunately, other social networks include people who oppose tobacco smoking, and provide reinforcement for avoiding tobacco, possibly countering the industry influences. These include culture-wide sanctions.

Culture-wide "values" define social contingencies that may delimit smoking. One of the more prominent is protecting infants and children from harm, especially if suffering from disease (for example, asthma). To the extent that PSE is viewed as harmful, the community is likely to criticise parents who allow their children to be exposed, especially if very young, ill, or in their own home.

At the legislative level, community policies and related policing and penalty systems can contribute to both direct change in tobacco use and communitywide social reactions to tobacco use and child exposure. Community policies restricting PSE in public buildings, and increasingly in outdoor public places, will reduce smoking and PSE in these environments, but it also may reduce smoking and PSE in private residences. ${ }^{4}$ Public building polices may also prompt non-smokers to criticise smokers and to ask them to stop or move from the area. This change in reactions to smoking may generalise to other settings, including private homes, and to the extent that it does, it becomes another cultural contingency impacting smokers' behaviour. Thus, families may be susceptible to social contingencies to delimit their children's PSE, as the larger society adopts cultural standards prohibiting PSE.

One means of protecting children from PSE is the establishment of "policies" restricting smoking in the home. These can be created by parents or they may eventually be created by the larger society. The study by Spencer and colleagues $^{5}$ in this issue extends the literature on PSE exposure based on harm reduction concepts. It shows that children show lower cotinine levels for families who have "no-smoking policies" which restrict all smoking from their home. This strengthens the case for protecting children in their home by promoting residential bans or polices disallowing all cigarette smoking in the home.

However, unlike policies for public buildings, parent residential policies are not enforced by police, employers, building owners, or government agencies. Parents must remove ashtrays, set up signs, and most importantly ask family members and visitors to not smoke or go outside. Coaching interventions show promise for assisting parents in reducing their children's PSE, but these procedures have not yet emphasised formal residential policies. ${ }^{6}$ The skills and social contingencies operating for individual mothers or fathers to effect these assertive practices are not captured in the concept of "home policies". In order to advance the field of PSE control, the specific assertive practices and the conditions that influence them must be identified and engineered to support parents' establishment of such policies. For instance, can a mother restrict the child's grandmother from smoking in the home; can she do so if the grandmother owns the home? Can she do so, if too poor to move to another residence? Additional research is needed to answer these questions and inform efficacious means of promoting home policies and the behaviour that defines them. Such research is urgent. The ill health effects warrant aggressive efforts to reduce PSE in homes.

As the damage due to PSE has become more evident, agencies that protect the public, such as the judicial system, have begun to delimit PSE for children from parents who are divorcing. ${ }^{7}$ As this precedent increases, it will promote other agencies to consider the effects of PSE. The logical extension will be Child Protective Services for neglect or abuse. These institutional interventions deliver severe penalties, such as potential loss of custody of a child. Since the smoking parents, grandparents, and friends are themselves addicted victims of the industry, the use of such severe penalties and their initial selective use in divorce cases or in low income and racial/ethnic minority families, raises risk of prejudicial penalties, making these families a more severe victim of the tobacco industry. This is a questionable use of aversive consequences to alter parenting practices. ${ }^{8}$ To offset these relatively draconian penalties, it is vital that the assertive practices necessary to eliminate tobacco from residences be promoted based on empirical evidence of efficacious interventions that emphasise positively reinforcing contingencies, even if the parents do not quit smoking.

In any case, the courts assignment of custody based, in part, on PSE is already influencing parents' smoking and adoption of residential policies. As court penalties become more common and more publicised, they will fuel and justify social sanctions from the public for child PSE. Thus, a cumulative cascade of contingencies is already evolving and how these will compete with the aggressive counter media and counter lobbying of the tobacco industry remains to be seen. It also remains to be seen how public health research can insert more positive means of establishing residential bans in homes to protect children and all family members.

Since most of the ill effects from PSE come from cumulative exposure of even very low doses (for example, $<1.0 \mathrm{ng} / \mathrm{ml}$ of urine cotinine), and since effects include serious illness, disability, and early death, the social evolution of penalties for child PSE may be the 
natural and required early process of curtailing tobacco use, PSE, and the industry that engineers both. This is even more profoundly true when epidemiological studies show that remarkably low doses (for example, less than one part per million) of known toxins, such as benzene, can disrupt progenitor cell function. ${ }^{9}$ Since benzene is only one of thousands of such toxins in PSE, this supports the physiological causal path to illness and death. It also accelerates both professionals' and lay audiences' conviction that PSE is too harmful to allow, even if in incredibly small doses.

However, behavioural research must provide parents with the skills and reinforcement to effect change in their homes to protect their children. Behavioural science must also inform community-wide policies that will support parents' efforts to reduce PSE in their homes, without requiring severe penalties. Otherwise, the harm produced by the tobacco industry will extend to the trauma that parents will experience at the loss of child custody.

The Spencer et al study provides relatively strong evidence of the value of residential policies restricting all tobacco to outside the home. This sets the stage for determining how to equip parents with the skill and ability to do so, without incurring severe penalties.
Movement in this direction will also inform a broader restriction of the tobacco industry.

PSE is completely preventable by elimination of the tobacco industry. Community policies that use positive means of promoting parents to adopt home policies restricting tobacco smoke in the home will contribute to the prevention of children's and others' ill health. This may also be a critical step towards generating a culture that is both anti-tobacco and anti-tobacco industry, creating a public that would lobby for complete elimination of the industry. In the meantime, research must be directed to incremental reduction in PSE for children and all family members, and doing so might lead to the ultimate preventive policy.

Arch Dis Child 2005;90:661-662.

doi: 10.1136/adc.2004.069534

\section{Authors' affiliations}

M Hovell, J Daniel, Center for Behavioral Epidemiology and Community Health, San Diego State University, California, USA

Correspondence to: $\operatorname{Dr} M$ Hovell, Center for Behavioral Epidemiology and Community Health, San Diego State University, California, USA; mhovell@projects.sdsu.edu

Competing interests: none declared

\section{REFERENCES}

1 California Environmental Protection Agency. Health effect of exposure to environmental tobacco smoke. Final report. Sacramento, CA Office of Environmental Health Hazard Assessment, 1997.

2 US Department of Health and Human Services. The health consequences of smoking: a report of the surgeon general, US Department of Health and Human Services, Centers for Disease Control and Prevention, National Center for Chronic Disease Prevention and Health Promotion, Office on Smoking and Health, 2004.

3 Hovell MF, Wahlgren DR, Gehrman C. The behavioral ecological model: integrating public health and behavioral science. In: DiClemente RJ, Crosby R, Kegler M, eds. New and emerging models and theories in health promotion and health education. San Francisco, CA: Josey-Bass Inc, 2002.

4 Borland R, Chapman S, Owen N, et al. Effects of workplace smoking bans on cigarette consumption. Am J Public Health 1990;80:178-80.

5 Spencer N, Blackburn C, Coe C, et al. Parent reported home smoking bans and toddler (18-30 month) smoke exposure: a cross-sectional survey. Arch Dis Child 2005;90:670-4

6 Gehrman CA, Hovell MF. Protecting children from ETS exposure: a critical review. Nicotine Tob Res 2003:5:289-301.

7 Igbenebor J. Smoking as a factor in child custody cases. Journal of the American Academy of Matrimonial Lawyers 2002; 18:235-52.

8 Botelho R, Fiscella K. Protect children from environmental tobacco smoke: but avoid stigmatization of parents: a commentary on Pyle et al. (2005). Families Systems and Health 2005;23(1):17-20.

9 Lan Q, Zhang L, Li G, et al. Hematotoxicity in workers exposed to low levels of benzene. Science 2004;306:1774-6.
$\mathrm{NO}_{2}$ is not the most potent gaseous oxidant, and causes less airway inflammation than ozone. ${ }^{5}$ Recent research has therefore focused primarily on other pollutants. However, all combustion processes in air directly produce oxides of nitrogen (for example, $\mathrm{NO}_{2}$ and $\mathrm{NO}_{\mathrm{x}}$ ). $\mathrm{NO}_{2}$ is also formed when nitrogen oxide (NO), emitted from vehicle exhausts, reacts with atmospheric ozone. Thus winter $\mathrm{NO}_{2}$ peaks are associated with low wind speeds and temperature inversions, whereas summer $\mathrm{NO}_{2}$ peaks are associated with ozone peaks during hot sunny days. In the UK, half of $\mathrm{NO}_{2}$ emissions are from road transport, and emissions have fallen from $2744 \mathrm{kt}$ in 1990 to $1728 \mathrm{kt}$ in 2000 . Widespread exceedences of the $40 \mu \mathrm{g} / \mathrm{m}^{3}$ annual mean limit remain, and are projected to continue over the next decade. ${ }^{6} \mathrm{~A}$ causal relation between $\mathrm{NO}_{2}$ and SIDS would therefore be an important stimulus for $\mathrm{NO}_{2}$ reduction strategies. However, as Klonoff-Cohen and colleagues ${ }^{4}$ acknowledge, there are some important limitations to their data. First, individual exposure was at best approximate, with concentrations in some cases extrapolated for monitoring stations several kilometres from the home. Nerriere and colleagues ${ }^{7}$ compared known variable is that infants have a higher minute ventilation relative to lung surface area. ${ }^{3}$ Thus for the same pollutant concentration, infants' airadults. Howeve a higher expos associated with air pollution has not colleagues ${ }^{4}$ in this issue is therefore study the authors found that monthly sudden infant death syndrome (SIDS) counts tracked with monthly averaged centrations, and that high levels of $\mathrm{NO}_{2}$ over the preceding 24 hours was a significant risk factor for SIDS Effects were also observed for carbon monoxide (CO), but these were less consistent. 
personal $\mathrm{NO}_{2}$ exposure with extrapolated levels from central monitoring stations, and concluded that ambient $\mathrm{NO}_{2}$ concentrations should be used "with caution" in assessing individual exposure-rightly pointing out that a major source of $\mathrm{NO}_{2}$ is gas cooking. Second, the association between $\mathrm{NO}_{2}$ and SIDS may be confounded by correlated pollutants such as inhaled particles, ${ }^{8}$ or an unrecognised social variable with a high spatial correlation with outdoor $\mathrm{NO}_{2}$. Indeed, concomitant emissions of $\mathrm{NO}_{2}$ and $\mathrm{CO}$ from vehicle exhausts 9 may account for the association between $\mathrm{CO}$ and SIDS. Third there is no biological explanation for a mechanism of interaction between $\mathrm{NO}_{2}$ and SIDS, although in the past uncertainty about mechanisms has not been a barrier to successful SIDS reduction interventions. ${ }^{10}$ One possible explanation is that $\mathrm{NO}_{2}$ alters the pulmonary immunological response to trivial viral infections - an interaction that has been reported for asthmatic children. ${ }^{11}$ Nevertheless, Klonoff-Cohen and colleagues' study, ${ }^{4}$ whose findings are compatible with a recent Canadian report which found a significant association between daily rates of SIDS and increased $\mathrm{NO}_{2}$ (and $\mathrm{SO}_{2}$ ) on the previous day, ${ }^{12}$ should help to refocus researchers' attention on gaseous pollutants, and young children as an important vulnerable age group. The methodological issues of research in this age group are challenging, ${ }^{12}$ but newly developed computer models which calculate gaseous emissions and their dispersion at the spatial level of individual households, ${ }^{13}$ may allow reanalysis of pre-existing birth cohort datasets. Until more data become available, no specific recommendations can be given to parents who are concerned about reducing the risk of SIDS. Wide variations in $\mathrm{NO}_{2}$ occur within small spatial areas, and both avoiding exposure and living a normal life is virtually impossible. It may well be that regulators concerned about the potential health impact of $\mathrm{NO}_{2}$ on young infants should not concentrate on this single pollutant, but aim to reduce all combustion products emitted within suburban areas. However, when developing exposure reduction policies, data on the association between $\mathrm{NO}_{2}$ and SIDS will be important in any health impact analysis.

Arch Dis Child 2005;90:662-663. doi: 10.1136/adc.2004.068379

Correspondence to: Dr J Grigg, Division of Child Health, Department of Infection, Immunology and Inflammation, University of Leicester, PO Box 65, Leicester LE2 7LX, UK; ig33@le.ac.uk

Competing interests: none

\section{REFERENCES}

1 Grigg J. The health effects of fossil fuel derived particles. Arch Dis Child 2002;86:79-83.
2 Donaldson K, MacNee W. Potential mechanisms of adverse pulmonary and cardiovascular effects of particulate air pollution (PM10). Int J Hyg Environ Health 2001;203:411-15.

3 Developmental toxicity: special considerations based on age and developmental stage. In: Etzel RA, Balk SJ, eds. Pediatric environmental health. Elk Grove Village, IL: American Academy of Pediatrics, 2003:9-23.

4 Klonoff-Cohen H, Lam PK, Lewis A. Outdoor carbon monoxide, nitrogen dioxide, and sudden infant death syndrome. Arch Dis Child 2005;90:750-3.

5 Wigle DT. Outdoor air. In: Child health and the environment. Oxford: Oxford University Press Inc, 2005:300-33

6 Air Quality Expert Group. Executive summary. In: Air Quality Expert Group, ed. Nitrogen dioxide in the United Kingdom. London: Department for Environment, Food and Rural Affairs, 2004:9-14.

7 Nerriere E, Zmirou-Navier D, Blanchard O, et al. Can we use fixed ambient air monitors to estimate population long-term exposure to air pollutants? population long-term exposure to air pollutants? study. Environ Res 2005;97:32-42.

8 Tong S, Colditz P. Air pollution and sudden infant death syndrome: a literature review. Paediatr Perinat Epidemiol 2004;18:327-35.

9 Green E, Short S, Shuker L, et al. Carbon monoxide from vehicle exhaust and the exchange of indoor and outdoor air. In: Green E, Short S, eds. Indoor air quality in the home (2): Carbon monoxide. Leicester: Institute for Environment and Health, 1998:52-64.

10 Taylor BJ. A review of epidemiological studies of sudden infant death syndrome in southern $\mathrm{New}$ Zealand. J Paediatr Child Health 1991;27:344-8.

11 Chauhan AJ, Inskip HM, Linaker $\mathrm{CH}$, et al. Personal exposure to nitrogen dioxide (NO2) and the severity of virus-induced asthma in children. Lancet 2003:361:1939-44.

12 Dales R, Burnett RT, Smith-Doiron M, et al. Air pollution and sudden infant death syndrome. Pediatrics 2004; 113:e628-31.

13 Mukherjee P, Viswanathan S. Carbon monoxide modeling from transportation sources. Chemosphere 2001;45:1071-83.
The natural history of UTIs probably started to change in the 1950s with the advent of antibiotics and development of paediatric services. The radiological anomalies associated with recurrent UTIs, particularly vesicoureteric reflux and renal scarring, were described by Hodson and Edwards. ${ }^{4}$ The high rate of detection of vesicoureteric reflux and renal scarring in children investigated following UTI prompted a call for routine imaging tests in all children following UTI in an attempt to detect high risk cases early and thus prevent avoidable renal scarring. This strategy assumed that renal scarring was both acquired and preventable, that vesicoureteric reflux and infection combined was the cause of renal damage, and that high risk cases could be clearly identified at an early stage through imaging tests such as intravenous urography and micturating cystography.

In the past two decades many of these assumptions have been challenged. Some children with vesicoureteric reflux and small or scarred kidneys have congenital renal defects that cannot be prevented by ureteric reimplantation or impaired renal function. Long term follow up studies have supported this impression, and in a significant proportion of children and adults, end stage chronic pyelonephritis ${ }^{3}$ Such often collected over many years and describing the constellation of sy toms to other health professionals, with a view to identifying diseases and syndromes and starting to understand syes and prevention. These studies were not generally epidemiological studies but highly selected groups who showed the most severe or persistent symptoms. 
prophylactic antibiotics. $^{5}$ Three important studies comparing reimplantation with prophylactic antibiotics failed to show benefit from ureteric reimplantation, and there are no controlled studies comparing prophylaxis with intermittent short course treatment for UTI. ${ }^{6}$ Even the value of prophylaxis in preventing UTIs has now been challenged and there have never been studies to test the effectiveness of prophylaxis in the prevention of scarring. ${ }^{7}$

Over the past three decades there have been several reports of the nonspecific symptoms of UTI in infants, and it has become clear that many cases have been missed, some in hospital and more in primary care. ${ }^{8}$ This situation has changed gradually and sick children and infants with fever, vomiting, or failure to thrive are now usually tested for urine infection if they attend hospital and sometimes in primary care. Parents have increased expectations for referral to a hospital or paediatrician as an emergency if their child is unwell so that relatively few children are left untreated for long periods with symptomatic UTIs.

Children are often offered imaging and prophylactic antibiotics after the first UTI, based on the assumption that a third will have VUR, in line with the published guidelines of the Royal College of Physicians. ${ }^{9}$ This is based on the premise that they are at increased risk of recurrent UTIs and that scarring in these children will be prevented by prophylaxis. However these assumptions are unproven and the potential value of imaging and prophylaxis in this group may well be different from the groups described in earlier studies.

Symptomatic UTI in infancy and childhood is now recognised as a common problem among healthy children affecting around $6-7 \%$ of girls and $2-3 \%$ of boys. ${ }^{10}$ Since the publication of the guidelines in 1991, huge resources have been expended on referring young children to paediatricians and on to radiologists for imaging, which for children in the first year includes DMSA scanning and cystography. This latter test is particularly distressing, time consuming, expensive, invasive, and involves radiation. ${ }^{11}$ VUR may be missed in up to $15 \%$ of cases, and there is a significant risk of introducing bacteria and causing UTI. To justify these risks to the patient and use of resources there should be clear benefits from this test and the subsequent interventions.
In this issue, Moorthy et al describe the outcome of cystography in 108 children after the first UTI in the presence of a normal ultrasound examination. ${ }^{12}$ Although VUR was detected in $12 \%$ of renal units we are not told how many patients were affected. Abnormal DMSA scans were found in 4/25 (16\%) refluxing renal units and 8/216 (4\%) non-refluxing renal units. They used simple statistical tests to show that in the population studied, the presence of VUR is not a useful way of identifying children at high risk of renal scarring. These results are different from the historical reports on which current practice is based. It is useful to consider possible reasons for these differences.

The children described by Moorthy et al are all under 12 months and many will have been referred following the first UTI. They are younger and probably healthier than children described in the early studies. We are not told how urine was collected or what culture methods were used in the laboratory; however, unless invasive samples are collected by catheter or suprapubic puncture it is likely that there were some false positive samples. Although from a purely scientific view point this might be seen as a weakness, this represents the situation in many children's units in the UK. This could explain the relatively low incidence of VUR in this study. Similarly this could have contributed to the low prevalence of renal scarring detected. All children with anomalies of the urinary tract including single kidneys and urinary tract dilatation were excluded prior to the analysis.

In conclusion, a number of factors have been identified that may explain the difference between the results of the study by Moorthy et al and the results from historical observational studies. These factors include improved health care such as greater awareness of UTI in infancy, better diagnosis and earlier treatment of UTI, the widespread availability and use of antibiotics, and better child health surveillance. Differences between the populations described in terms of age, number of previous UTIs, presence of congenital anomalies detectable on ultrasound, and available health care can account for significant differences in prevalence of additional abnormalities detected at cystography and DMSA scans. Common sense dictates that it is inappropriate to use high volume high cost resources on invasive tests on healthy children after recovery from relatively trivial illness in the absence of evidence of benefit. A change in practice with greater emphasis on earlier detection and treatment of UTIs in the first year of life and less emphasis on imaging after the event is more likely to be effective in preventing renal damage as well as minimising the adverse effects of acute illness. This point has been made by the York Centre for Reviews and Dissemination in their recent publication on diagnosing urinary tract infection following a Health Technology Assessment. ${ }^{13}$

Arch Dis Child 2005;90:663-664.

doi: 10.1136/adc.2004.067330

Correspondence to: Dr K Verrier Jones, Children's Kidney Centre for Wales, University of Wales College of Medicine, Heath Park, Cardiff CF14 4XN, Wales, UK; verrier-jones@ cf.ac.uk

Competing interests: none declared

\section{REFERENCES}

1 Weiss S, Parker F. Pyelonephritis: its relationship to vascular lesions and arterial hypertension. Med Intern 1939;18:221-315.

2 Stansfeld JM. Clinical observations relating to incidence and aetiology of urinary-tract infections in children. BMJ 1966;5488:631-4.

3 Habib R, Broyer M, Benmaiz H. Chronic renal failure in children. Causes, rate of deterioration and survival data. Nephron 1973;11:209-20.

4 Hodson CJ, Edwards D. Chronic pyelonephritis and vesico-ureteric reflex. Clin Radiol 1960;11:219-31.

5 Risdon RA. The small scarred kidney in childhood. Pediatr Nephrol 1993;7:361-4.

6 Wheeler D, Vimalachandra D, Hodson EM, et al. Antibiotics and surgery for vesicoureteric reflux: a meta-analysis of randomised controlled trials. Arch Dis Child 2003;88:688-94.

7 Williams G, Lee A, Craig J. Antibiotics for the prevention of urinary tract infection in children: a systematic review of randomized controlled trials. J Pediatr 2001;138:868-74.

8 Van Der Voort JH, Edwards AG, Roberts R, et al. Unexplained extra visits to general practitioners before the diagnosis of first urinary tract infection: a case-control study. Arch Dis Child 2002;87:530-2.

9 Royal College of Physicians. Guidelines for the management of acute urinary tract infection in childhood. Report of a working group of the Research Unit. JR Coll Physicians Lond $1991 ; 25: 36-42$

10 Jakobsson B, Esbjorner E, Hansson S. Minimum incidence and diagnostic rate of first urinary tract infection. Pediatrics 1999;104(2 pt 1):222-6.

11 Phillips DA, Watson AR, MacKinlay D. Distress and the micturating cystourethrogram: does preparation help? Acta Paediatr 1998:87:175-9.

12 Moorthy I, Easty M, McHugh K, et al. The presence of vesicoureteric reflux does not identify a population at risk for renal scarring following a first urinary tract infection. Arch Dis Child 2005:90:733-6.

13 Anon. Diagnosing urinary tract infection (UTI) in the under fives. Effective Health Care 2004;8:1-11. 